Elliot T. Hudes MD FRCPC, Howard J. Marans MD M SC, Gail M. Hirano MD FRCPC, Andrew C. Scott MB FFARCS, Ken Ho MD FRCPC

\section{Recovery room oxy- genation: a comparison of nasal catheters and 40 per cent oxygen masks}

Many factors contribute to postoperative hypoxia. These include smoking, position, ${ }^{1}$ obesity, ${ }^{2}$ age ${ }^{3}$ and surgical site $^{4,5}$ Hypoxia can follow even minor surgery under general anaesthesia. ${ }^{6}$ It has been proposed that early hypoxia which lasts for hours, and is seen in the recovery room, is caused by anaesthetic factors such as the effects of somnolence, narcotics and neuromuscular relaxants. Prolonged hypoxia lasting for days is determined by such factors as surgical site and other manifestations of the patient's physical status.?

Recently it has been appreciated that even the short period of time when the patient breathes room air en route to the recovery room is enough to precipitate hypoxaemia. ${ }^{8-10}$ Cyanosis is not a consistent finding during hypoxia and should not be relied upon. ${ }^{9,11,12}$ The use of oxygen in the recovery room to treat and prevent hypoxia is critical. Until recently in our institution a single lumen nasal catheter with distal eye was given to the patient either nasally or via the oral airway until the patient was awake. Oxygen was delivered at $4 \mathrm{~L} \cdot \mathrm{min}^{-1}$. If the anaesthetist felt the patient had a significant risk of hypoxia, a 40 per cent oxygen venturi face mask at $8 \mathrm{~L} \cdot \mathrm{min}^{-1}$ was used.

The purpose of this study was to compare the efficacy of the nasal catheter versus a 40 per cent oxygen venturi face mask in treating postoperative hypoxia. As well, epidemiologic data were collected to identify risk factors associated with hypoxia on arrival in the recovery room.

\section{Methods}

The study was approved by our institution's medical evaluation committee. Because pulse oximetry readings are a routine method of noninvasive patient evaluation in our recovery room we did not seek informed consent.

One hundred and sixty-one ASA physical status I-III patients undergoing elective surgery as inpatients and day surgery cases were evaluated. Excluded from the study were patients having airway, thoracic, major vascular, cardiac, or neurosurgery. Patients with preoperative hypoxia $\left(\mathrm{PO}_{2}<60 \mathrm{mmHg}\right)$, a history of central nervous 
system or musculoskeletal disease affecting respiration were excluded. Patients who showed signs of airway obstruction, coughing or cardiovascular instability, on the way to or in the recovery room, also were excluded from the study.

The pulse oximeters used were the Physiocontrol Lifestat 1600 and the Ohmeda Biox 3700 in the operating rooms and the Nellcor model $\mathrm{N}-10$ in the recovery room.

All patients received a general anaesthetic given by one of four anaesthetists well acquainted with the study design. They were free to choose any agents or techniques appropriate for the patients' status and surgery. All patients were monitored intraoperatively with a pulse oximeter by finger probe. After the anaesthetic was terminated, the effects of neuromuscular relaxants were reversed with a cholinesterase inhibitor. Full neuromuscular recovery was confirmed with a sustained contraction in response to a five-second tetanic stimulus at $50 \mathrm{~Hz}$. If fade was present the patients were excluded from the study. Before transfer to the recovery room, all patients were oxygenated with. 100 per cent oxygen via mask or endotracheal tube for a minimum of three minutes. An oximetry reading was noted prior to transfer. Upon arrival in the recovery room, the patients were randomly assigned to one of threc groups. These groups were: oxygen by a single \#10 french nasal catheter with distal eye (Unoplast model 0193) at $4 \mathrm{~L} \cdot \mathrm{min}^{-1}$, catheter via oral airway at $4 \mathrm{~L} \cdot \mathrm{min}^{-1}$, or a 40 per cent venturi face mask at $8 \mathrm{~L} \cdot \min ^{-1}$, (Introtech Resources Inc.). The patient had an immediate pulse oximetry reading using a finger probe whilst breathing room air and was then given oxygen. The reading was repeated at 15 minutes on the chosen therapy.

It became obvious during the study that patients on a catheter via an oral airway would wake up quickly and remove their airways before the 15 minutes elapsed. The catheter was reapplied via the nose and the data for the oxygen via oral airway and nasal catheter were pooled.

The anaesthetist filled out a study data sheet which recorded the patient's ASA status, age, and sex. Specific risk factors were sought by recording the operation performed, history of obstructive lung disease, asthma, smoking, and obesity. Obesity was defined as weight greater than 20 per cent of predicted ideal body weight. The premedications were none $(\mathrm{n}=43)$, meperidine $1 \mathrm{mg} \cdot \mathrm{kg}^{-1}$ combination with either perphenazine 1.25 $2.5 \mathrm{mg}$ or promethazine $12.5-25 \mathrm{mg}$ intramuscularly (n = 54), morphine 10-15 mg with perphenazine $2.5 \mathrm{mg}$ intramuscularly $(\mathrm{n}=4)$, or diazepam $0.1-0.2 \mathrm{mg} \cdot \mathrm{kg}^{-1}$ $P O(n=60)$. The anaesthetic drugs, use of intermittent positive pressure ventilation or spontaneous ventilation and endotracheal intubation or mask use were listed. Use of a relaxant other than succinylcholine for intubation was recorded. A specific breakdown on the use of fentanyl was documented. The range was none, less than 2 $\mu \mathrm{g} \cdot \mathrm{kg}^{-1}, 2-5 \mu \mathrm{g} \cdot \mathrm{kg}^{-1}$, or greater than $5 \mu \mathrm{g} \cdot \mathrm{kg}^{-1}$.

The statistical analysis performed, using the $z$ (normal) and chi-square statistics, was divided into two sections. The first is an evaluation of the mask versus catheter data using $z$-statistics for proportional data. The second involved an analysis of the potential risk factors associated with hypoxia on arrival in the recovery room using contingency tables based on chi-square statistics for all except age which was analyzed using the Student's $t$ test. As multiple statistical testing was required the alpha level (p) for each test was necessarily decreased. An overall level of less than 0.05 for the study could be achieved.

\section{Results}

Recovery room arrival data were available for 161 patients. The mean age was 40.2 years (range $8-85$ years). Forty-nine were male and 112 female. One hundred and four patients had peripheral surgery while 26 had upper and 31 lower abdominal surgery.

Thirty-four patients (21.1 per cent) arrived in the recovery room hypoxic $\left(\mathrm{SaO}_{2}<90\right.$ per cent $)$, while 127 (78.9 per cent) were considered adequately oxygenated. Mean saturation in the hypoxic group was 85.2 per cent (range 75-89 per cent) and in the normoxic group was 94.5 per cent (range $90-100$ per cent). As a result of this clinically and statistically significant difference ( $p$ $<0.001$ ), the two groups were analyzed separately when comparing mask versus catheter therapy

In the hypoxic group 12 patients received mask therapy and 22 patients were randomized to catheters. The mean saturations on arrival in recovery room were comparable for the mask and the catheter groups, therefore no bias existed. Fifteen minutes after arrival in the recovery room all 34 patients were adequately oxygenated (see Table I). The remaining 127 patients who arrived with adequate oxygenation consisted of 57 patients treated with the 40 per cent $\mathrm{O}_{2}$ mask and 70 in the catheter group. Again, the mean saturations on arrival in the recovery room were comparable for the mask and catheter group. One of the 70 patients in the catheter group (1.4 per cent) was hypoxic after 15 minutes, while all the mask patients remained adequately oxygenated. Therefore, there were no statistically significant differences found $(p>0.10)$ between mask and catheter therapy during the first 15 minutes of recovery room stay in either of the two groups (arriving hypoxic or normoxic).

Several of the epidemiologic factors studied were found to be associated with hypoxia on arrival in the recovery room ( $p<0.001$ ) (see Table II). The significant factors were obesity, increased age, ASA physical 
TABLE 1 Comparison of mask versus catheter $\mathrm{O}_{2}$ therapy in the recovery room

\begin{tabular}{|c|c|c|c|c|}
\hline & $\begin{array}{l}\text { No. of } \\
\text { patients }\end{array}$ & $\begin{array}{l}\text { Mean } \mathrm{SaO}_{2} \\
\text { on arrival } \\
\pm S D\end{array}$ & $\begin{array}{l}\text { Hypoxic at } \\
15 \mathrm{~min}\end{array}$ & $\begin{array}{l}\text { Mean } \mathrm{SaO}_{2} \\
\text { at } 15 \mathrm{~min} \\
\pm S D\end{array}$ \\
\hline \multicolumn{5}{|c|}{ Hypoxic group $(n=34$ ) } \\
\hline Mask & 12 & $84.3 \pm 4.05$ & 0 & $96.7 \pm 2.15$ \\
\hline Catheters & 22 & $85.7 \pm 3.06$ & 0 & $96.6 \pm 2.48$ \\
\hline \multicolumn{5}{|c|}{ Arrived adequately oxygenated $(n=127)$} \\
\hline Mask & 57 & $94.3 \pm 2.38$ & 0 & $97.8 \pm 1.74$ \\
\hline Catheters & 70 & $94.6 \pm 2.43$ & 1 & $97.5 \pm 2.67$ \\
\hline
\end{tabular}

status $>I$, the use of premedication and the method of ventilation (endotracheal tube with intermittent positive pressure ventilation). Factors for which no association could be demonstrated included gender, smoking, chronic obstructive lung disease, operative site, use of neuromuscular relaxants and dose of narcotics during anaesthesia. All of the factors found to be statistically significant were associated with an alpha level $<0.001$.

\section{Obesity}

Nineteen patients ( 11.8 per cent) in the study were obese. Over half of these patients were found in the hypoxic group. 32.4 per cent (11 patients) of the hypoxic group were obese compared with only 6.3 per cent (eight patients) of the normoxic group

\section{Age}

The hypoxic patients tended to be older with a mean 47,4 years (range 8-84) compared with the younger adequately oxygenated group, 38.3 years (range $17-85$ ).

\section{ASA physical status}

Almost two thirds of the patients in this study (64.6 per cent) had an ASA status of 1 . There were 57 patients ( 35.4 per cent) with an ASA status of II or III. In the hypoxic group 67.6 per cent (23 patients) had an ASA status of II or III while only 26.8 per cent (34 patients) in the adequately oxygenated group had an ASA status $>$ I.

\section{Premedication}

Most of the patients in the hypoxic group (33 patients, 97.1 per cent) received premedication on the ward before their operation compared with only 66.9 per cent (85 patients) in the adequately oxygenated group.

\section{Method of ventilation}

Over 40 per cent ( 68 patients) of the patients in this study had a mask anaesthetic with spontaneous ventilation while the remainder had an endotracheal tube (ETT) and intermittent positive pressure ventilation (IPPV). A high-
TABLE II Factors associated with hypoxia on arrival in recovery room

Significant

Obesity

Age

ASA status

Use of premedication

Intermittent positive pressure ventilation and endotracheal tube

Not significant

Gender

Smoking

Chronic obstructive lung disease

Operative site

Dosage of narcotics during anaesthesia

er percentage of hypoxic patients ( 76.5 per cent, 26 patients) had the latter form of ventilation (IPPV) compared with the adequately oxygenated group ( 52.8 per cent, 67 patients).

\section{Discussion}

The diagnosis of hypoxia was designated to be any pulse oximetry reading less than but not equal to 90 per cent. At 90 per cent saturation the $\mathrm{PO}_{2}$ has been equated in many studies to $58 \mathrm{mmHg}{ }^{7,8}$ This is only true at normal temperature and $\mathrm{pH}$. The oxyhaemoglobin dissociation curve will vary with temperature and acid base status. Mild hypothermia and hypercarbia are frequent sequelae in the patient awakening from general anaesthesia. To establish that a patient was hypoxic, we set hypoxia at less than or equal to a $\mathrm{SaO}_{2}$ of 89 per cent.

The different pulse oximeters used in this study will yield similar results as they have been shown to be accurate even at low saturations. ${ }^{13}$ We found that 21 per cent of patients arrived in the recovery room hypoxic. Other studies quote an incidence of 28-35 per cent. ${ }^{8,9}$ Had we included those patients with $\mathrm{SaO}_{2}$ of 90 per cent, our study would also reflect a similar incidence.

The venturi mask is an effective way to administer a set $\mathrm{FlO}_{2}$ of enriched oxygen. It is also much more expensive 
than a simple nasal catheter. The nasal catheter delivers an $\mathrm{FIO}_{2}$ which is difficult to control. We found in our patient population that both therapies were effective in treating hypoxic patients and maintaining normoxia in the rest of the patients. The mean $\mathrm{SaO}_{2}$ on catheters versus masks at 15 minutes was not significantly different. Previous literature deals well with identifying postoperative hypoxia and its causes but there are no studies examining the efficacy of any oxygen therapies. We recommend that inexpensive nasal catheters be used on the majority of patients in the recovery room.

It is appreciated that postoperative hypoxia is secondary to a reduction in functional residual capacity (FRC). When the closing capacity exceeds the FRC, small airway closure creates areas of low V/Q, atelectasis and physiologic shunting resulting in a lower $\mathrm{PO}_{2}{ }^{14-16}$

There appears to be a bimodal array of factors that influence postoperative hypoxia. Hypoxia in the first few hours postoperatively is often secondary to anaesthetic factors. ${ }^{7}$ The hypoxia that lasts for days is a function of the site of surgery and patient characteristics. Upper abdominal surgery causes hypoxia that is more profound than lower abdominal or peripheral surgery. 4,5,14-16 Although we had an insufficient number of patients to demonstrate that the surgical site was a statistically significant risk factor the percentage of patients with upper abdominal incisions in the hypoxic group exceeded those in the normoxic group (14.7 versus 11.8 per cent).

Our study compares favourably with that of Tyler $e t$ al. who studied oxygenation of patients during transfer to the recovery room. ${ }^{8}$ In addition to demonstrating that postoperative hypoxia was not associated with anaesthetic agents or a history of smoking, there was a significant association between hypoxia and obesity.

In the study by Morris et al. postoperative hypoxia as detected by pulse oximetry was associated with obesity. ${ }^{17}$ Also, we confirm their findings of a higher prevalence of hypoxia with increased age and increased ASA physical status. This may reflect a decreased FRC and increased closing volume in the elderly. ${ }^{3}$ Their study also found that postoperative hypoxemia was more common when anaesthesia exceeded 90 minutes, after body cavity surgery, or when more than 1.5 litres of fluid was given.

The study by Pullerits et al. studying desaturation in children during transfer to the recovery room reinforces our findings that the type of anaesthetic and use of narcotics were not risk factors. ${ }^{9}$ They did not find controlled ventilation (IPPV) a factor but we have. We examined our data looking for bias and found that $68.6 \mathrm{per}$ cent of premedicated patients had an ETT with IPPV versus $\mathbf{2 7 . 9}$ per cent of unpremedicated patients. Also,
25.4 per cent of premedicated patients had an upper abdominal incision versus 2.3 per cent of unpremedicated patients. Therefore premedicated patients were more likely to have an ETT with IPPV and abdominal surgery. The data for the different groups of premedications were pooled into one group. Because of the bias it is difficult to predict whether these factors are independent risk factors, and this will need further study.

\section{Acknowledgement}

Thanks to Mrs. Jean Cole and the recovery room nurses without whose help this study would not have been possible.

\section{References}

1 Stieder DJ, Murphy R, Kazemi $H$. Mechanism of postural hypoxemia in asymptomatic smokers. Am Rev Resp Dis 1969; 99: 760-6.

2 Vaughan $R$ W, Engelhardt RC, Wise L. Postoperative hypoxemia in obese patients. Ann Surg 1974; 180: 877-82.

3 Kizamura $H$, Sawa $T$, Ikezono E. Postoperative hypoxemia: the contribution of age to the maldistribution of ventilation. Anesthesiology 1972; 36: 244-52.

4 Ali $J$, Khan TA. The comparative effects of muscle transection and median and upper abdominal incisions on postoperative pulmonary function. Surg Gynecol Obstet 1979; 148: 863-6.

5 Diament ML, Palmer KNV. Postoperative changes in gas tensions of arterial blood and in ventilatory function. Lancet 1966; 2: 180-2.

$6 \mathrm{Nunn} J F$, Payne $J P$. Hypoxaemia after general anaesthesia. Lancet 1962; 2: 631-2.

7 Marshall $B E$, Millar $R A$. Some factors influencing postoperative hypoxaemia. Anaesthesia 1965; 20: 408-28.

8 Tyler IL. Tantisira B. Winter PM, Motoyama EK. Continuous monitoring of arterial oxygen saturation with pulse oximetry during transfer to the recovery room. Anesth Analg 1985; 64: 1108-12.

9 Pullerits J, Burrows FA, Ray WL. Arterial desaturation in healthy children during transfer to the recovery room. Can I Anaesth 1987; 34: 470-3.

10 Kararia BK, Harnik EV, Mitchard R, Kim Y, Admed S. Postoperative arterial oxygen saturation in the pediatric population during transportation. Anesth Analg 1988; 67: $280-2$.

11 Coté CI, Goldstein EA, Coté MA, Hoaglin DC, Ryan JF. A single blind study of pulse oximetry in children. Anesthesiology 1988; 68: 184-8.

12 Comroe JH, Botelho $S$. The unreliability of cyanosis in the recognition of arterial anoxemia. Am J Med Sci 1947: 214: 1-6. 
13 Severinghaus $J W$, Naifeh $K H$. Accuracy of response of six pulse oximeters to profound hypoxia. Anesthesiology 1987; 67: 551-8.

14 Craig $D B$. Postoperative recovery of pulmonary function. Anesth Analg 1981; 60: 46-52.

15 Spence AA, Alexander $J$. Mechanisms of postoperative hypoxaemia. Proc Roy Soc Med 1972; 65: 6-8.

16 Alexander JI, Spence AA, Parikh RK, Stuart B. The role of airway closure in postoperative hypoxaemia. Brit $J$ Anaesth 1973: 45: 34-40.

17 Morris RW, Buschman A, Warren DL, Philip JH, Raemer $D B$. The prevalence of hypoxemia detected by pulse oximetry during recovery from anesthesia. J Clin Monit 1988; 4: $16-20$.

\section{Résumé}

Cent soixante et un patients classe ASA I-III devant subir des chirurgies électives ont été étudies pour comparer l'efficacité du cathérer nasal versus le masque venturi à 40 pour cent d'oxygène. Vingt et un pour cent des patients sont arrivés à la salle de réveil avec une hypoxie telle que mesurée par saturomètre $\left(\mathrm{SaO}_{2}<90\right.$ pour cent). Quinze minutes plus tard tous les patients qui sont arrivés hypoxiques furent bien axygénés selon la thérapie d'oxygénation choisie. Seulement un patient qui est arrivé avec une oxygénation adéquate devint hypoxique quinze minutes après l"urilisation d'un catheter nasal. Il $n$ ' y avait aucune différence statistique entre les patients qui ont reçu 40 pour cent d' oxygène par masque et les patients qui ont reçu l"oxygène par cathéter nasal. $\mathrm{La} \mathrm{SaO}_{2}$ moyenne du groupe ayant reçu 40 pour cent d'oxygène par masque d̀ 15 minutes était de $96.7 \pm 2.15$ pour cent versus $96.6 \pm 2.48$ pour cent pour le cathéter nasal. Le cathéter nasal était aussi efficace que les masques dे 40 pour cent pour le traitement de l'hypoxie dans la salle de réveil. L'abésité et l'áge étaient des facteurs de risque statistiquement significatifs chez les patients qui sont arrivés en hypoxie. L'âge moyen des patients du groupe hypoxique était de $47.4 \pm 15.6$ ans versus $38.3 \pm 15.6$ ans pour le groupe non-hypoxique $(p<0.001)$. Les patients ayant un tube endotrachéal avec ventilation à pression positive intermittente ou une prémédication étaient plus aptes à être hypoxiques a l'arrivée. Ces deux facteurs étaient étroitement associés et peuvent ainsi démontrer un biais. Les autres facteurs comme le sexe, le rabagisme, la présence des maladies pulmonaires obstructives chroniques autre que l'asthme, le site de l'incision et le type de l'anesthésie n'étaient pas des facteurs de risque statistiquement significatifs. 